\title{
红树林土壤 $\mathrm{pH}$ 和其他土壤理化性质之间的相互作用
}

\author{
沙聪 ${ }^{1,2}$, 王木兰 ${ }^{1,2}$, 姜玥璐 ${ }^{1^{*}}$, 林光辉 ${ }^{1,3}$
}

1. 清华大学深圳研究生院, 深圳 518000 ;

2. 清华大学环境学院, 北京 100084 ;

3. 清华大学地球系统科学系, 地球系统数值模拟教育部重点实验室, 北京 100084

* 联系人, E-mail: jiang.yuelu@sz.tsinghua.edu.cn

2018-04-18 收稿, 2018-05-24 修回, 2018-05-25 接受, 2018-07-19 网络版发表

国家自然科学基金(41474032)、国家自然科学基金青年科学基金(41506129)和深圳市科技创新委计划项目(JCYJ20170412171959157, JCYJ20150529164918736, JCYJ20150831192329178)资助

摘要红树林生态系统具有强大的固碳、储碳能力, 在防治污染、净化水体和维持生物多样性等方面也发挥着 重要作用。然而在气候变化和人类活动双重影响下, 红树林生态系统正面临着面积锐减、生态系统结构简化、生 物多样性降低、生态功能退化等巨大考验。红树林湿地土壤的理化性质如 $\mathrm{pH}$ 、养分含量及盐度等直接或间接影响 着红树林的生长状况和生态功能. 红树林土壤中 $\mathrm{pH}$ 和其他理化性质之间的相互关系, 除了两个因素之间相互作用 外, 也同样受其他理化条件的影响. 红树林土壤 $\mathrm{pH}$ 只有维持在合理范围, 才能维持和提高红树林生态系统的固碳 作用, 发挥其强大的固碳功能. 红树林土壤通常多是酸性硫酸盐土, 硫含量较高, 土壤 $\mathrm{pH}$ 与全硫含量一般呈负相 关关系. 红树的数量、种类、密度、分布以及种群结构都直接影响着土壤中的硫含量, 而土壤的氧化状态、硫含 量及硫化物的种类和分布又是决定土壤 $\mathrm{pH}$ 的重要因素, 同时 $\mathrm{pH}$ 也影响土壤中硫化物的赋存状态. 红树林土壤中 有机物的摄入和分解是不断进行的过程, 其中有机碳的含量和种类通过影响土壤细菌的种群结构、生长、生理过 程, 进而影响土壤 $\mathrm{pH}$; 同时, 土壤 $\mathrm{pH}$ 的平衡又影响着红树林土壤中的有机碳含量和种类. 高含盐的红树林土壤的 $\mathrm{pH}$ 与盐度之间, 一般呈正相关关系; 然而盐度到底是直接影响, 还是间接影响了 $\mathrm{pH}$ 的变化, 还有待进一步研究. 因此, 探索红树林土壤理化性质的相互关系具有重要意义. 本文首先以 $\mathrm{pH}$ 为切入点, 综述了红树林湿地土壤 $\mathrm{pH}$ 和 其他理化性质之间的相互关系和作用, 包括 $\mathrm{pH}$ 与硫含量、有机碳、盐度、溶解氧以及 $\mathrm{N} 、 \mathrm{P}$ 含量的相互关系. 然后 探讨了气候变化和人类活动可能对红树林土壤 $\mathrm{pH}$ 产生的影响. 最后, 尝试通过上述内容, 推理出土壤 $\mathrm{pH}$ 和其他理 化性质对具体的气候变化现象和人类活动(如海平面上升、红树林重建等)可能做出的响应. 本文涉及的研究内容 和分析方法对于发挥红树林储碳能力、修复和重建红树林都具有重要的参考意义.

关键词红树林, 气候变化, 人类活动, $\mathrm{pH}$, 养分含量

红树林湿地大多分布于热带、亚热带沿海潮间 带, 在消浪护岸、防治污染、净化水体、优化沿海环 境、维持生物多样性和海岸带生态平衡等方面发挥着 重要作用 ${ }^{[1]}$, 也因其强大的固定 $\mathrm{CO}_{2}$ 的能力而被誉为

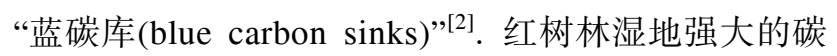
汇能力主要有两方面重要原因: 一是它生产力水平
极高 ${ }^{[3]}$, 可以吸收利用大量的 $\mathrm{CO}_{2}$, 这一过程的顺利 进行需要湿地土壤提供足够的营养; 二是红树林湿 地土壤中有机碳分解速率低, 碳储存时间长, 这使得 湿地土壤具有强大的捕获、固定 $\mathrm{CO}_{2}$ 的能力 ${ }^{[2,4]}$, 而有 机碳的稳定性和分解快慢也与土壤性质息息相关. 因此, 红树林湿地土壤的理化性质对进一步了解湿

引用格式: 沙聪, 王木兰, 姜玥璐, 等. 红树林土壤 $\mathrm{pH}$ 和其他土壤理化性质之间的相互作用. 科学通报, 2018,63: 2745-2756

Sha C, Wang M L, Jiang Y L, et al. Interactions between pH and other physicochemical properties of mangrove sediments: A review (in Chinese). Chin Sci Bull, 2018, 63: 2745-2756, doi: 10.1360/N972018-00369 
地碳循环过程及其碳汇能力非常重要.

红树林是重要的碳汇场所, 具有强大的生态功 能, 同时也是生态敏感带. 近年来由于气候变化和人 类活动的影响, 红树林湿地面临面积锐减、生态系统 结构简化、生物多样性降低、生态功能退化等严重问 题 ${ }^{[5]}$. 2006年, 澳大利亚世界红树林大会上, 专家们 一致认为也许不到 100 年的时间, 我们就将失去红树 林及其生态系统提供的各种资源 ${ }^{[6]}$. 气候变化和人类 活动对红树林生态系统的影响是复杂的、多样的且无 法忽视的, 其影响主要有两种方式: 一是直接影响红 树植物; 二是通过改变红树林土壤理化性质, 间接影 响红树林生态系统. 本文以 $\mathrm{pH}$ 为中心, 总结了红树 林土壤理化性质是如何相互影响并达到相对平衡, 为研究气候变化和人类活动影响下红树林土壤理化 性质的变化及其动态平衡提供了理论依据.

\section{1 红树林土壤 $\mathrm{pH}$ 和其他理化因子的相互作用}

红树林土壤中的各理化性质(如 $\mathrm{pH}$ 、溶解氧、盐 度、S、P、N含量等)之间有着复杂的相互关系, 形成 不断变化的动态平衡系统. 在红树林土壤理化动态 平衡中, $\mathrm{pH}$ 可能是具有决定作用的因素, 占据着重要 地位 ${ }^{[7]}$. 研究表明, 红树林湿地土壤 $\mathrm{pH}$ 主要受潮汐效 应、土壤中有机物含量 ${ }^{[8]} 、 \mathrm{Eh}^{[7]}$ 、土壤含硫量 ${ }^{[9]}$ 等因 素的影响; 同时, 红树林与海岸线的距离、与河流的 距离, 雨季中淡水对海水的稀释, 盐度和气温的降 低, 有机物质的降解等外界因素都极大地影响着 $\mathrm{pH}^{[10,11]}$. 图 1 以 $\mathrm{pH}$ 为中心, 总结了红树林土壤各理化 性质之间的相互关系和作用.

\section{1 土壤硫含量与pH的相互作用}

红树的化学组成中硫含量很高, 平均达 $0.4 \%$ 左 右, 这一特征对土壤发生及其性质有巨大的影响 ${ }^{[9]}$, 因此红树林土壤通常都是酸性硫酸盐土. 有研究表 明, 在红树林表层土壤中 $(0 \sim 10 \mathrm{~cm})$, 红树高密度的 活性根将导致土壤次氧化/氧化、黄铁矿氧化、土壤 酸化等现象 ${ }^{[12]}$, 这表明土壤中的硫很大一部分是来 源于红树植物的活性根. 何琴飞等人 ${ }^{[13]}$ 对钦州湾不 同类型红树林的土壤因子进行了测算和分析, 发现 随着土壤硫含量的增加, 土壤 $\mathrm{pH}$ 呈对数下降, 相关 性达到极显著水平; 龚子同和张效朴 ${ }^{[9]}$ 的研究也认 为, 土壤 $\mathrm{pH}$ 与全硫含量呈负相关关系.

除了上述所说硫化物含量对土壤 $\mathrm{pH}$ 有显著影响,
硫化物的种类和分布对 $\mathrm{pH}$ 的影响则更为直接和具体. 土壤中的可氧化硫化物 (黄铁矿、黄钾铁矾等), 在土壤 脱水通气氧化后产生大量硫酸, 致使土壤酸化, 土壤 $\mathrm{pH}$ 急剧下降 ${ }^{[9]}$; 同时土壤干燥生境中, 硫氧化细菌对 低价硫化物的氧化作用使 $\mathrm{pH}$ 进一步降低, 甚至可达 $3 \sim 2.4^{[14]}$, 究其原因就是土壤中硫氧化细菌的存在改 变了土壤硫化物的分布. 在恒温氧化还原体系中, Eh 由氧化剂与还原剂的活度比决定: 氧化剂所占的比 例越大, Eh值越高, 则氧化强度越大; 反之, 则还原 性越强. Eh的高低直接影响硫化物的氧化, 进一步影 响 $\mathrm{pH}$ 的高低. 因此, 在红树林土壤中, 土壤的氧化状 态和硫含量都是决定土壤 $\mathrm{pH}$ 的重要因素.

当然, 红树林土壤中 $\mathrm{pH}$ 与全硫含量的负相关关 系 ${ }^{[9]}$ 并不是硫对 $\mathrm{pH}$ 单方向影响的结果, $\mathrm{pH}$ 也会影响 土壤中硫化物的赋存状态. 硫酸盐还原菌和硫氧化 细菌分别会把高价态硫化物还原为低价态和把低价 态硫化物氧化为高价态. 这两种细菌是影响硫化物 赋存状态的主要微生物类群, 同时 $\mathrm{pH}$ 又是限制这两 种微生物数量和活性的重要因素之一.

红树的数量、种类、密度、分布以及种群结构直 接影响着土壤中的硫含量, 同时土壤中的硫含量又 影响着红树林土壤的 $\mathrm{pH}$. 红树种植数量越多、密度越 大, 越会促使土壤 $\mathrm{pH}$ 向降低的方向发展. 深人了解 这些影响对全面评价红树林土壤 $\mathrm{pH}$ 在土壤理化性质 中的作用和位置、土壤 $\mathrm{pH}$ 对红树林生态系统稳定性 的影响具有重要意义; 尤其在红树林重建工程中, 研 究土壤硫含量与 $\mathrm{pH}$ 的相互作用, 有利于更加科学、合 理的规划和安排红树林种植种类、密度及分布结构. 目前, 对不同生境下(例如温度、潮汐状况、污水排 人情况、其他营养元素含量), 土壤 $\mathrm{pH}$ 与硫有效态含 量的关系和相互影响规律相关研究仍较少, 二者的 相互作用及变化对红树林土壤其他理化性质的影响 也需要更多的研究来验证.

\section{2 土壤有机碳与pH的相互作用}

红树林最大特点之一就是能通过有机碳摄人和 分解的综合作用, 在土壤中储存大量的有机碳 ${ }^{[15]}$. 红树林土壤中有机碳和 $\mathrm{pH}$ 之间也存在相互作用的关 系(图1).

一方面, 红树林土壤中有机碳的含量和种类会 影响土壤 $\mathrm{pH}$. 有机碳的种类和数量影响着土壤细菌 的种群结构、生长、生理过程, 进而影响土壤 $\mathrm{pH}$. 


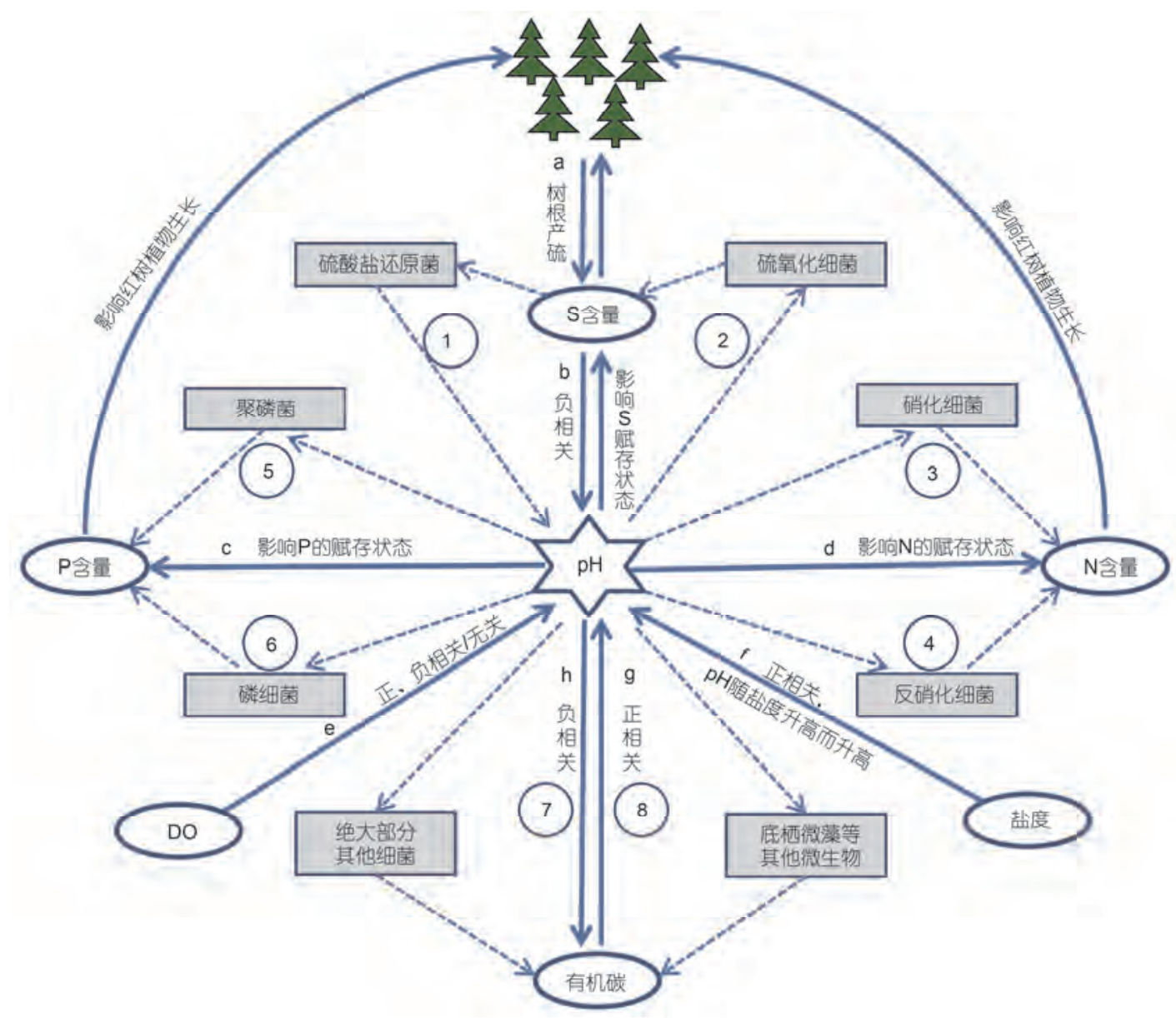

图 1 (网络版彩色)红树林土壤一些主要理化性质的相互关系. (1) 硫酸盐还原菌的硫酸盐还原反应; (2) 硫氧化细菌的硫氧化反应; (3) 硝化 细菌的硝化作用; (4) 反硝化细菌的反硝化作用; (5) 磷细菌的聚磷反应; (6) 磷细菌的释磷反应; (7) 绝大部分其他细菌分解有机物的过程; (8) 底栖微藻分解有机物的过程. a, 红树树根产硫, 红树越多, 土壤硫含量越高; b, 在同样的氧化条件下, 硫含量越高, $\mathrm{pH}$ 越低; $\mathrm{c}, \mathrm{pH}$ 影响含磷化 合物的存在形态; $\mathrm{d}, \mathrm{pH}$ 影响含氮化合物的存在形态; e, 不同的研究得出不同的结论(DO和 $\mathrm{pH}$ 分别表现出正、负相关和无关的数量关系); f, pH 随盐度升高而升高; $\mathrm{g}$, 其他条件不变, 有机碳含量增加将导致 $\mathrm{pH}$ 升高; $\mathrm{h}$, 其他条件不变, $\mathrm{pH}$ 降低, 将导致有机碳含量升高

Figure 1 (Color online) Interactions among several key physicochemical properties of mangrove sediments. (1) Sulfate reduction by sulfate-reducing bacteria; (2) sulfur oxidization by sulfur-oxidizing bacteria; (3) nitrification by nitrobacter; (4) denitrification by denitrifier; (5) phosphorus accumulation by phosphobacteria; (6) phosphorus releasing by phosphobacteria; (7) organic matter decomposition by microorganisms; (8) organic matter decomposition by benthic microalgae. a, Sulfur accumulation in mangrove sediments. The more the mangroves, the higher the sulfur level in sediments. $\mathrm{b}$, The higher sulfur level in sediments, the lower $\mathrm{pH}$ in the same oxidizing condition. $\mathrm{c}, \mathrm{pH}$ influences the status of phosphorous compounds. $\mathrm{d}$, $\mathrm{pH}$ influences the status of nitrogenous compounds. e, Different studies lead to different conclusions: $\mathrm{pH}$ may show positive, negative and independent relationships with dissolved oxgen. $\mathrm{f}, \mathrm{pH}$ increases with increasing salinity. $\mathrm{g}$, Increasing organic matter level can induce the increase in $\mathrm{pH}$. $\mathrm{h}$, Decreased $\mathrm{pH}$ can induce the increase in organic matter level

Jayalath等人 ${ }^{[8]}$ 在实验室条件下模拟了雨季和干季, 并在雨季和干季分别对红树林土壤投加不同种类的 有机物. 研究发现, 雨季投加植物秸秆等有机物, 土 壤 $\mathrm{pH}$ 呈升高趋势; 而干季投加植物秸秆, 土壤 $\mathrm{pH}$ 先 出现了下降趋势, 然后上升, 最终也会达到比空白对 照更高的土壤 $\mathrm{pH}^{[8]}$. 也就是说，在特定条件下，土壤 中有机物含量的增加可以刺激硫酸盐还原反应, 土 壤 $\mathrm{pH}$ 升高, 从而改善土壤理化条件; 而干季土壤 $\mathrm{pH}$
与有机物含量没有像雨季那样呈现简单的正相关关 系, Jayalath等人 ${ }^{[8]}$ 给出的解释是, 在该模拟条件下, $\mathrm{pH}$ 降低是因为在干季之前的湿季, 土壤积累了 $\mathrm{FeS}$ 或 者 $\mathrm{FeS}_{2}$, 其被氧化使土壤 $\mathrm{pH}$ 减低. 如果将实验室模 拟扩展到实地研究, 可能会发现干湿季也存在明显 的不同，如干季土壤干燥会影响土壤的通气率，土壤 含氧量升高会促进硫酸盐的氧化作用; 又如, 干季时 降水量小, 海水盐度与雨季相则较高, 这些因素变化 
也会影响红树林土壤的 $\mathrm{pH}$. 另外, 除土壤有机碳含 量, 土壤有机物种类和特征(如分子量和 $\mathrm{C} / \mathrm{N}$ 比等)也 直接影响土壤 $\mathrm{pH}$ 的变化 ${ }^{[8]}$. 如前一小节所述, 红树林 土壤中发挥主要作用的是硫酸盐还原菌, 其常利用 易降解有机物 (如分子量较低的有机物) ${ }^{[16]}$, 将硫酸盐 等氧化态硫转换为还原态硫, 进而改变土壤的 $\mathrm{pH}$. 当土壤中有机物 $\mathrm{C} / \mathrm{N}$ 比约为 10 时, 硫酸盐还原菌活性 最大, 最有利于微生物对有机物的降解 ${ }^{[17,18]}$. 有机碳 的含量和种类对于土壤 $\mathrm{pH}$ 的影响也并不是简单的单 向关系, 这一作用还需考虑土壤其他理化性质的影 响, 包括土壤 $\mathrm{pH}$ 原本的状态. 有研究表明, 当 $\mathrm{pH}<4.5$ 时, 硫酸盐还原剂活性较低, 向土壤中投加有机物并 不能有效提高 $\mathrm{pH}$; 而当土壤 $\mathrm{pH}>4.5$ 时, 向土壤中投 加有机物能更高效地促进硫酸盐还原反应的发生 ${ }^{[16]}$. 由此可以推理出, 若想通过增加有机碳含量提高 $\mathrm{pH}$, 达到优化土壤条件的目的, 需要先利用外界因素将 土壤 $\mathrm{pH}$ 调整到 4.5 左右. 例如, 潮汐效应就是改变 $\mathrm{pH}$ 的重要外界因素之一. 有研究表明, 在高潮位淹没时 间较长时, 红树林土壤 $\mathrm{pH}$ 上升, 酸度有所减轻, 如果 此时向红树林添加适当的有机碳(如植物秸秆等), 能 够有效地提高 $\mathrm{pH}^{[8]}$. 一定条件下, 有机物的投加可以 改善红树林土壤的 $\mathrm{pH}$ 并进而影响其他土壤理化性质, 但投加有机物对红树林重建是否有正面作用, 或是 否可以通过投加有机物来提高红树林净化污染水体 效率这些方面研究仍鲜少关注.

另一方面, 土壤 $\mathrm{pH}$ 也影响着红树林土壤中有机 碳含量和种类. 红树林土壤中有机物的摄人和分解 不断进行, 这两个过程都受到土壤 $\mathrm{pH}$ 的影响, 同时 其平衡也决定了红树林土壤中的储碳量. 红树林土 壤系统摄人有机碳的形式多种多样, 比如垃圾、腐烂 根茎、根的分泌液和微生物体等形式, 红树调落物、 浮游植物和底栖微藻等都是红树林生态系统碳循环 的重要组成部分 ${ }^{[19]}$; 而红树林土壤中有机碳的分解 主要依靠微生物或中型土壤生物 ${ }^{[20]}$. 郭志华等人 ${ }^{[21]}$ 对海南清澜港红树林分布区进行采样, 分析 $\mathrm{pH}$ 对有 机物含量的影响, 发现河口区土壤有机碳含量与土 壤 $\mathrm{pH}$ 均呈显著负相关 $(P<0.05)$, 即土壤有机碳含量 随土壤 $\mathrm{pH}$ 升高而降低. 张文娟等人 ${ }^{[22]}$ 认为, 有机碳 之所以与 $\mathrm{pH}$ 呈负相关, 是因为土壤 $\mathrm{pH}$ 直接影响土壤 中微生物的种类、数量和活性, 例如在酸性土壤中, $\mathrm{pH}$ 限制了微生物的种类多样性, 降低了有机质的分 解速率; 红树林土壤 $\mathrm{pH}$ 的升高(酸性区间内)又可导
致红树林土壤中有机碳大量分解, 以 $\mathrm{CO}_{2}$ 的形式释放 到大气中, 从而加重温室效应. 所以, 红树林土壤 $\mathrm{pH}$ 值只有维持在合理范围, 红树林才能发挥其强大的 固碳功能.

土壤有机物对 $\mathrm{pH}$ 影响的研究, 对重建红树林、维 护生物多样性、净化污染水体等方面都有重要的理论 和应用价值; 土壤 $\mathrm{pH}$ 对有机物含量和组成的影响、减 少土壤碳释放的最适土壤 $\mathrm{pH}$ 范围等对维持和提高红 树林生态系统的固碳作用具有重要意义. 目前对红 树林碳含量、 $\mathrm{CO}_{2}$ 通量与土壤 $\mathrm{pH}$ 的关系, 以及影响它 们之间动态平衡因素的研究仍鲜少报道.

\section{3 盐度对 $\mathrm{pH}$ 的影响}

红树林分布的沿海地带土壤含盐量通常较高, 而不同的红树植物对于土壤的盐度和 $\mathrm{pH}$ 适应范围也 各不相同 ${ }^{[23]}$. 红树林分布离岸的距离、与淡水源的距 离、所处位置的海拔高度、潮汐现象的频率强度等因 素, 也都会对红树林土壤盐度产生显著影响, 从而或 直接或间接地影响红树林土壤的 pH. Satheeshkumar 和 Khan ${ }^{[11]}$ 通过对印度Pondicherry沿岸红树林的水文 数据分析认为, 低盐低温的环境将导致红树林土壤 $\mathrm{pH}$ 值偏低. 刘荣成 ${ }^{[24]}$ 通过对泉州湾河口湿地的红树 林湿地土壤理化性质进行了研究, 发现当淡水注人 较少、人类活动影响较小且红树林土壤盐度只受潮汐 影响下, 土壤 $\mathrm{pH}$ 和盐度呈明显的正相关关系. 红树 林土壤盐度与 $\mathrm{pH}$ 之间的正相关关系, 究竟是因为盐 度对 $\mathrm{pH}$ 的直接影响作用, 还是因为潮汐作用引人海 水影响了盐度, 使土壤酸度减小, 间接影响 $\mathrm{pH}$, 还有 待进一步研究(图1).

另外, 潮汐现象除了影响红树林土壤的盐度, 还 会影响红树林土壤的其他理化性质. 潮汐通过将富 氧海水、微生物、悬浮体(TSS)、可溶物质和营养盐 输人红树林沉积物, 进而影响土壤的多种理化性质; 潮汐作用还可促进降解产物和微生物在土壤中的输 运 ${ }^{[25]}$. 由于潮汐现象本身复杂性, 其对红树林土壤 理化性质的影响可能是通过物理、化学、生物等多渠 道、多界面共同作用实现，相关过程和机理的研究仍 需要大量的实验进行验证.

\section{4 溶解氧(DO)与pH的相互作用}

红树林土壤中溶解氧(dissolved oxygen, DO)不 但影响红树林土壤中微生物的活性及 $\mathrm{N}$ 和 $\mathrm{P}$ 等营养元 
素的存在形态, 同时也影响土壤的 $\mathrm{pH}$, 其相互作用 如图1所示.

同一环境中红树林土壤各理化性质互相作用、互 相影响, 任何两种理化因素的相互作用同时还受其 他环境因素影响; 同样, $\mathrm{DO}$ 和 $\mathrm{pH}$ 之间的关系不仅仅 是这两个因素简单的相互作用, 也同样受其他理化 条件的影响. Boto和Bunt ${ }^{[26]}$ 在对澳大利亚昆士兰红树 林区域的研究中发现, 红树林土壤 $\mathrm{DO}$ 和 $\mathrm{pH}$ 具有显著 的线性正相关关系. Boto和Bunt ${ }^{[26]}$ 认为, DO和 $\mathrm{pH}$ 的 正相关关系主要是由于溶解性有机物的中间作用, 并提出了两个可能原因: (1) 弱酸在空气氧化的过程 中, 同时降低了土壤的 $\mathrm{pH}$ 和DO; (2) 土壤 $\mathrm{pH}$ 降低可 使土壤中有机碳含量增加 (如 1.2所述), 进而增强细 菌的呼吸和代谢, 最终降低土壤含氧量. 然而, Satheeshkumar和Khan ${ }^{[11]}$ 在对印度南部红树林水体及 沉积物的多项理化性质的研究结果却显示, 红树林 土壤 $\mathrm{DO}$ 和 $\mathrm{pH}$ 呈负相关关系, 可能因其研究的红树林 区域受潮汐影响较大, 即该红树林区域淹水期较长, 导致土壤水环境 $\mathrm{pH}$ 有上升趋势, 而溶解氧则因水淹 表现出降低趋势. Yuwono等人 ${ }^{[27]}$ 对印度尼西亚红树 林的研究发现, 红树林土壤 $\mathrm{DO}$ 和 $\mathrm{pH}$ 并不具有显著的 相关关系, 但该研究中数据较少, 并不能得到确定的 结论.

红树林土壤 $\mathrm{DO}$ 和 $\mathrm{pH}$ 的相互关系也因特定生境、 研究地区、调查时间的不同, 迄今仍没有得到统一的 变化规律. 红树林土壤 $\mathrm{DO}$ 和 $\mathrm{pH}$ 之间相互作用受有机 物含量、潮汐作用等理化条件影响较大, 因此到底哪 些因素起决定协调作用还需要实验数据及对更多红 树区域研究的支持和验证.

\section{$1.5 \mathrm{pH}$ 对营养盐的影响}

磷和氮是红树植物和土壤微生物生存、生长必需 营养盐. pH对P和 N在红树林沉积物中的存在数量、赋 存形式具有重要的决定作用(图1). $\mathrm{pH}$ 变化能打破原 有磷酸盐矿物的溶解平衡, 使得平衡向沉淀生成或 者沉淀溶解的方向移动, 其改变决定着土壤中有效 磷及各种矿物质磷的含量.

在红树林沉积物的酸性土壤中, 黄铁矿在有氧 条件下氧化形成酸性硫酸盐土, 降低P的生物有效 性, 使 $\mathrm{P}$ 成为生长的限制因子 ${ }^{[28]}$. 目前许多研究认 为, 磷酸盐矿物的溶解度受 $\mathrm{pH}$ 影响 ${ }^{[7,29 \sim 31]}$. Gardner 等人 ${ }^{[29]}$ 认为, 一般植物根系会分泌出有机酸 (如柠檬
酸和苹果酸), 能将 $\mathrm{P}$ 从微溶的 $\mathrm{Al}, \mathrm{Fe}, \mathrm{Ca}$ 磷酸盐中分 离出来, 成为可溶含磷营养盐, 这一论点也佐证了 pH对土壤 $\mathrm{P}$ 含量的影响作用. $\mathrm{Ca}_{2}-\mathrm{P}, \mathrm{Ca}_{8}-\mathrm{P}$ 和 $\mathrm{Ca}_{10}-\mathrm{P}$ 的 转化也受到 $\mathrm{pH}$ 的直接影响: $\mathrm{pH}$ 越低, 上述几种磷酸 盐的速效磷含量则越高, 而 Al-P和 Fe-P则相反 ${ }^{[30]}$. Oxmann等人 ${ }^{[7]}$ 对西贡河三角洲红树林自然保护区的 研究表明, 即使沉积物 $\mathrm{pH}$ 变化范围极小(如 $\mathrm{pH}$ 6 7), 也能对红树林 $\mathrm{P}$ 循环产生巨大的影响. 红树林土壤中 的有效磷, $\mathrm{Ca}-\mathrm{P}, \mathrm{Al} / \mathrm{Fe}-\mathrm{P}$ 以及叶片中的磷含量都与土 壤 $\mathrm{pH}$ 有显著关系: (1) 当 $\mathrm{pH}<4$ 和 $\mathrm{pH}>6$ 时, $\mathrm{Ca}-\mathrm{P}$ 随 $\mathrm{pH}$ 上升而上升; 但当 $\mathrm{pH}$ 为4 6之间时, $\mathrm{Ca}-\mathrm{P}$ 几乎保持恒 定；(2) 当 $\mathrm{pH}$ 为 $3.3 \sim 6.8$ 时, $\mathrm{Al} / \mathrm{Fe}-\mathrm{P}$ 随 $\mathrm{pH}$ 的上升呈指 数上升趋势; 但 $\mathrm{pH}>6.8$ 时, $\mathrm{Al} / \mathrm{Fe}-\mathrm{P}$ 随 $\mathrm{pH}$ 的上升而下 降; (3) 当 $\mathrm{pH}$ 为 $3 \sim 8$ 时, $\mathrm{Ca}-\mathrm{P} /$ 有效磷比值与 $\mathrm{pH}$ 呈显著 负相关.

土壤中 $\mathrm{N}$ 主要有两个来源, 微生物固氮作用和微 生物对土壤有机物的降解作用, 这两个过程中微生 物都起着至关重要的作用 ${ }^{[25]}$. $\mathrm{pH}$ 是影响微生物生长 和活性的一个重要因素, 通过影响微生物活性还能 改变土壤中 $\mathrm{N}$ 摄取来源和数量; $\mathrm{pH}$ 还影响土壤 $\mathrm{N}$ 被摄 人后赋存形式及其被消耗情况.

土壤中硝化作用和反硝化作用可以改变土壤中 $\mathrm{N}$ 的存在形态和数量, 进而影响土壤 $\mathrm{pH}$ 及其他理化 因子. 硝化作用主要指 $\mathrm{NH}_{4}^{+}$在硝化细菌作用下, 依次 氧化为 $\mathrm{NO}_{2}^{-}$和 $\mathrm{NO}_{3}^{-}$的过程; 反硝化作用是指反硝化细 菌在缺氧条件下, $\mathrm{NO}_{3}^{-}$依次还原为 $\mathrm{NO}_{2}^{-}$和 $\mathrm{N}_{2}$ 的过程. 红树林土壤 $\mathrm{pH}$ 的变化既可以影响土壤的氧化条件, 又可以改变硝化细菌和反硝化细菌数量及活性. Oxmann等人 ${ }^{[7]}$ 的研究表明, 红树林土壤中 $\mathrm{N}$ 含量与 $\mathrm{pH}$ 值呈负相关关系. 这一负相关关系虽然目前仍未形 成比较统一的解释, 但通过对比干季和雨季结 果 $^{[7,32]}$, Oxmann等人 ${ }^{[7]}$ 发现土壤营养组分(包括 $\mathrm{N} 、 \mathrm{P}$ ) 与其他理化性质的相关关系相类似, 进而推测沿海 生态系统的生化稳定性(受干、雨季影响较小)主要受 潮汐状况的影响.

如果红树土壤被海水长时间浸没，土壤氧化环 境转弱, 则反硝化作用将占据明显优势, 大量 $\mathrm{NO}_{3}^{-}$盐 被还原为 $\mathrm{N}_{2}$, 土壤 $\mathrm{N}$ 含量降低，同时 $\mathrm{pH}$ 也因为长时间 被海水浸没而升高, 综合表现出的是 $\mathrm{pH}$ 与 $\mathrm{N}$ 含量的 负相关关系.土壤 $\mathrm{N}$ 和 $\mathrm{P}$ 含量都受土壤 $\mathrm{pH}$ 影响, 同时 也反作用于红树林的生长，进而又影响着土壤 $\mathrm{pH}$. 当然, 为了支持和证实这些推测, 需要更多观测数据 
和现场实验研究.

图 1 以 $\mathrm{pH}$ 为中心, 通过几种重要微生物的中间作 用把土壤各理化性质的相互关系进行了梳理, 总结 了它们之间的相互关系. 由此图可以看出, 土壤理化 性质直接影响土壤微生物的种类和数量; 反过来, 微 生物的分解作用、固定作用也都影响着营养元素的存 在数量和存在状态. 红树林各理化性质互相影响, 是 一个复杂的整体, 任意两个理化性质之间都不可能 简单地互相影响而不受其他条件的限制. 而现有研 究仍需要更系统的红树林土壤生态学研究, 其存在 问题主要有: (1) 红树林土壤理化性质研究, 缺少对 多个理化性质相互作用的全局性研究, 任何两个理 化性质之间的相互作用都同时受其他理化性质的影 响, 故探究多个理化性质之间的相互关系更具现实 意义; (2) 脱离具体生态环境条件的研究, 通常把理 化性质之间关系简单化, 而忽略了现实环境的复杂 性, 不同生境条件变化, 例如温度、潮汐状况、污水 排人情况, 对土壤理化性质之间的关系和相互影响 的规律会产生影响, 但目前系统考虑具体生境条件 变化影响的研究还较缺乏; (3) 对红树林土壤理化性 质现实意义的认识不足, 通过改变土壤理化性质可 以达到增加红树林储碳量、提高红树林重建效率等目 的, 但目前鲜少有研究涉及相关内容并加以应用. 为 了更深人研究红树林的生态功能, 深人挖掘红树林 土壤 $\mathrm{pH}$ 和多个理化因素之间的相互作用和关系就显 得尤为重要.

\section{2 气候变化对红树林土壤 $\mathbf{p H}$ 的影响}

全球气候变化可以表现在温度升高、海平面上
升、 $\mathrm{CO}_{2}$ 浓度改变、紫外线增强等方面 ${ }^{[33]}$, 这些方面 都直接或间接地影响红树林土壤的理化性质; 气候 变化也表现在台风的强度、频率增大 ${ }^{[34]}$ 和极端潮汐 事件增多, 进而影响红树林生态系统的稳定性 ${ }^{[35]}$. 图 2 总结了全球气候变化以及人类活动对红树林的 影响.

红树林土壤储存大量有机碳, 与其“有机碳分解 速率低”这一特点密不可分; 如果红树林土壤中有机 碳分解速度增加, 红树林湿地则很有可能由 “碳汇” 变成“碳源”. 随着全球气候变化以及人类活动影响 的增加, 红树林土壤的理化性质也不断发生改变, 红 树林的生长状况、土壤微生物数量和活性等也都在随 之变化, 这些变化又进一步影响红树林土壤理化性质.

\section{$2.1 \mathrm{CO}_{2}$ 浓度提高对红树林土壤 $\mathrm{pH}$ 的影响}

温室气体 $\mathrm{CO}_{2}$ 浓度提高对红树林的影响非常复 杂. Mckee等人 ${ }^{[36]}$ 曾预测, $\mathrm{CO}_{2}$ 浓度提高会刺激光合作 用和水利用效率, 从而提高红树林生长率. 对红树林 分布边界(纬度较高的地区)的研究结果也支持这一 观点 ${ }^{[35,37]}$. 但是这并不能适用于所有红树区域, 有研 究发现不同种的红树对 $\mathrm{CO}_{2}$ 升高的响应机制并不相 同 ${ }^{[38]}$. 另外, 大气中 $\mathrm{CO}_{2}$ 增加将导致海水的酸化, 红 树林被海水浸没部分土壤的 $\mathrm{pH}$ 也将随之有所降低, 土壤中 $\mathrm{C}, \mathrm{N}, \mathrm{P}$ 含量以及微生物的种类和分布也将随 之发生改变. 因此, 从如何维护并帮助红树林应对气 候变化角度来看, 土壤 $\mathrm{pH}$ 与其他理化性质之间的关 系研究具有重要意义. 但是, 目前针对不同纬度、不 同生境及不同红树种群和分布等情况, 红树林对 $\mathrm{CO}_{2}$ 浓度升高响应的研究还非常不足, $\mathrm{CO}_{2}$ 浓度提高对红

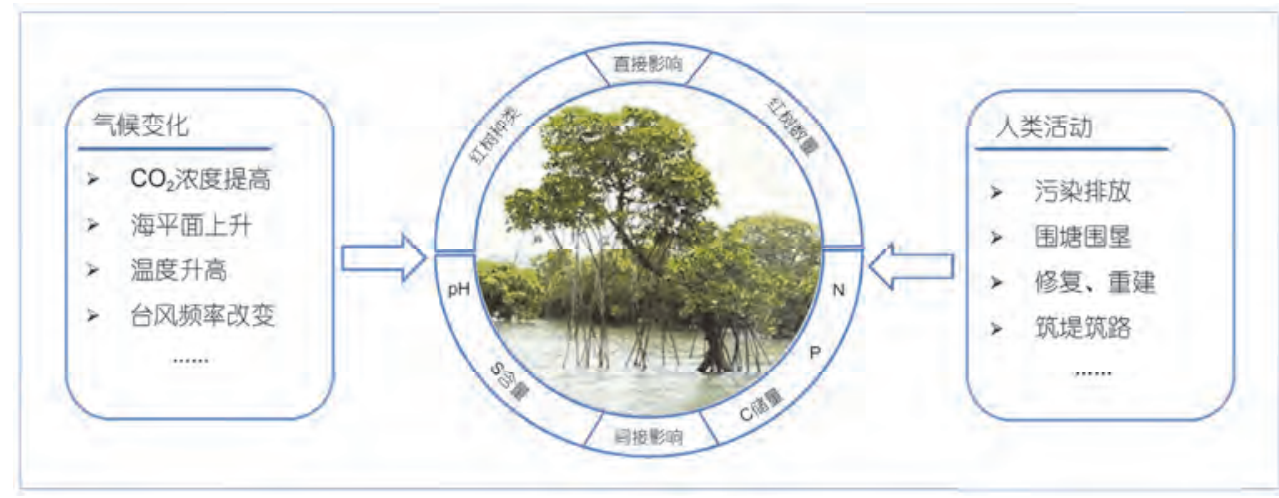

图 2 (网络版彩色)气候变化和人类活动对红树林的可能影响

Figure 2 (Color online) Possible impacts of climate change and anthropogenic activities on mangrove forests 
树林生长及红树林土壤 $\mathrm{pH}$ 的影响还有待进一步研究.

\section{2 海平面上升对红树林土壤 pH的影响}

全球气候变暖导致的陆源冰川和极地冰盖融解、 海水膨胀是导致全球海平面上升的主要原因, 其对 红树林土壤的理化性质也有重要的影响.

首先, 海水浸没时间的延长会直接改变红树林 土壤的盐度和溶解氧含量, 如前所述红树林土壤盐 度和溶解氧的变化又会影响红树林土壤 $\mathrm{pH}$ 和其他理 化性质 ${ }^{[11,23,24]}$; 其次, 海水浸没时间延长、浸没范围 扩大也会改变红树林土壤中微生物的种群结构和数 量. 恒河三角洲平原就是受全球变暖和海平面上升 影响的一个例子: 在平原中部, 与其他多数沿海地区 类似, 海平面的上升和海水漫过面积的扩大导致红 树林土壤盐度上升; 在平原西部, 则由于全球变暖导 致了喜马拉雅冰川的融化, 这使得红树林所处水环 境进一步淡化 ${ }^{[39]}$. 很多研究都致力于探究全球变暖 和海平面上升如何影响红树林生境的盐度 ${ }^{[39 \sim 41]}$, 并 且也证实了盐度的变化会改变红树植物地上部分的 生物量 ${ }^{[42]}$. 但是, $\mathrm{pH}$ 等其他重要理化性质对温度和 海平面上升的响应却鲜少涉及. 而这些研究将有助 于分析红树林生态系统面对气候变化会如何做出响 应以及响应的具体机理.

\section{3 人类活动对红树林土壤 $\mathrm{pH}$ 的影响}

全球工业化、经济发展以及城市化进程的加快, 在 创造了巨大经济效益的同时, 也对生态环境造成了巨 大的破坏, 红树林也未能幸免. 人类活动, 如农业用 地、围塘养殖、造陆生林、筑堤筑路、垃圾填埋、污 染排放等, 都对红树林生态系统造成了重大危害, 导 致红树林植被被破坏, 红树林物种丰度也受到极大的 影响 ${ }^{[6]}$. 虽然红树林湿地只占全球热带雨林面积的 $0.7 \%$, 但目前它的破坏却使得全球 $\mathrm{CO}_{2}$ 释放量增加了 10\%. Alongi和Mukhopadhyay ${ }^{[43]}$ 的研究表明, 目前红树 林的全球毁坏量年增长速率为 $1 \%$, 这导致每年有额外 的133 $\mathrm{Tg} \mathrm{C} / \mathrm{a}$ 被释放到大气中. 如图2所示, 人类活动 不仅能对红树林生态系统产生直接性的物理损伤, 还 可通过影响土壤性质和水文状况等条件造成间接影响.

\section{1 污染排放和水产养殖对红树林土壤 $\mathbf{p H}$ 的影响}

人类活动的增加打破了红树林生态系统平衡, 其中以污染排放和水产养殖对红树林土壤理化性质
的影响最为突出. 全世界范围内, 红树林生态系统都 被当作富营养化污水的处理、处置场所 ${ }^{[44]}$, 而污染排 放对于红树林生态系统有着复杂而深远的影响; 围 垦红树林以用于水产养殖是人类活动影响红树林生 长及生境的另一主要表现.

从污水处理的角度来说, 市政污水和水产养殖 污水中污染物质经过红树林净化之后, 有效减少 ${ }^{[45]}$; 但从红树林的角度来说, 其生态系统所受的影响则 复杂得多. 首先, 污水的引人能影响红树林土壤 $\mathrm{N}$, $\mathrm{P}, \mathrm{DO}$ 含量以及 $\mathrm{pH}$ 等多个理化性质的改变, 这与污水 本身的污染物组成有直接关系. 有研究表明, 污水投 人有利于红树林生态系统的特定生态功能, 投加污 水可以为红树林生态系统提供丰富的有机物以及氮、 磷等营养物质, 进而提高初级生产率和生物量 ${ }^{[46]}$. 理论上, 适量含营养元素污水的排放能优化红树林 的生长条件; 但是, 越来越多的研究表明, 污水排放 会对红树林生态系统造成负面影响. Lovelock等人 ${ }^{[47]}$ 的研究表明, 营养富集有利于红树林嫩枝的生长、提 高红树林的生长率, 但同时也降低了它们对不利环 境的适应能力. Boehm等人 ${ }^{[44]}$ 研究了城市污水排放对 红树林的影响, 发现营养富集能导致土壤缺氧: 一方 面影响红树植物、土壤微生物群落等的生存、生长; 同时还改变了红树林土壤 $\mathrm{pH}$ 等土壤理化性质, 对红 树林生态系统造成不可估量的消极影响.

除了污染排放, 围塘围层和水产养殖也是红树 林日益减少的一大原因. 有研究表明, 东南亚地区和 中国西南地区红树林迅速减少的主要原因不是气候 变化, 而是农业开筀和水产养殖 ${ }^{[48,49]}$. 水产养殖是红 树林地区常见围圼目的之一，同时，水产养殖污染又 成为影响红树林的主要污染源, 对红树林生态系统 产生一系列负面影响. 水产养殖污染主要包括残余 饵剂、动物废料和天然来源的有机物 ${ }^{[50]}$. 养殖污水中 $\mathrm{N}$ 和 $\mathrm{P}$ 过量是最受关注的问题之一. 如上所述, $\mathrm{N}$ 和 $\mathrm{P}$ 过量会导致沿海水环境的富营养化, 恶化红树林湿 地的水环境, 红树林土壤和水环境缺氧等 ${ }^{[1,52]}$. 红树 林土壤中 $\mathrm{N}, \mathrm{P}, \mathrm{DO}$ 含量的变化也会进一步影响土壤 $\mathrm{pH}$ 等理化性质. 随着人们对红树林重要性认识的逐 渐深人, 如何看待并解决红树林管理、保护和水产养 殖之间的矛盾成为了近年来研究人员关注的热点. Peng等人 ${ }^{[53]}$ 发现珠江河口东岸的红树林区域, 桐花 树(Egiceras corniculatum)因对长期淹没具有耐受性, 且能有效净化养殖水体, 也就是说, 桐花树可以适应 
低DO、高 $\mathrm{N}$ 、高P环境, 适合种植在水产养殖池塘里. 近年来提出的红树林-水产养殖综合系统 (the integrated mangrove-aquaculture system, IMAS), 将红树 林保护和高效水产养殖相结合, 但IMAS系统也仍然 存在诸多问题. 如何使污染排放、水产养殖等人类活 动和减轻红树林净化负担之间的矛盾达到平衡、优化 红树林的生长环境是一项艰难而有益的工作. 城市 污水和水产养殖污染排放对红树林影响的相关研究, 多数集中在污染对于红树林生态系统的宏观影响(如 生物量、死亡率等), 而其对土壤中营养元素、有机 物、土壤 $\mathrm{pH}$ 和其他理化性质的影响还需深人研究.

\section{2 红树林湿地生态修复与重建对红树林土壤 pH的影响}

鉴于红树林生态功能的重要性和日益减少的现 状, 国内外还开展了很多积极的人类活动, 包括通过 生物、生态和工程技术与方法, 人为改变或者停止生 态系统退化为主的红树林生态系统修复与重建 ${ }^{[54]}$.

下面就以红树林修复、重建常用的方法一人工 种植红树植物为例, 分析其可能带来的一系列红树 林土壤理化性质变化及影响(图3). 这一过程假设除 了红树植物增加, 其他外界条件没有发生明显改变 (如潮汐效应、 $\mathrm{O}_{2}$ 进人红树林所处水环境的量等): (1) 通过控制“红树种植量增加”这一单一变量, 土壤硫
含量随之增加，在同样的氧化条件下，土壤 $\mathrm{pH}$ 会相 应降低; (2) 随后发生多种土壤理化性质的改变, 包 括有机碳增加, 这也意味着 $\mathrm{CO}_{2}$ 释放量的减少; (3) 在一定 $\mathrm{pH}$ 范围内, 土壤 $\mathrm{N}$ 含量和生物有效 $\mathrm{P}$ 的增加, 这会进一步促进红树植物的生长繁殖. 虽然现实情 况中常常不会只发生单一因素的变化, 但这一分析 思路对于红树林研究、保护、管理的相关问题的简化、 分析、解决是有借鉴意义的.

气候变化和人类活动直接或间接地影响着红树 林湿地的生态功能. 一方面, 海平面上升、台风频率 改变等气候变化现象, 围塘围垦、红树林重建等人类 活动都会直接影响红树林的植被种类和生物量; 另一 方面, 气候变化和人类活动也会改变红树林所处水环 境和土壤环境的理化性质，从而间接地影响红树林的 生长状况及其生态功能. 表1总结了气候变化和人类 活动对红树林土壤理化性质可能的影响过程. 值得注 意的是, 表中所总结的理化性质之间相互作用、关系 来自于不同的研究, 因其对应的研究生境也不相同, 所以理化性质间相互作用、关系的变化规律也可能会 有所不同, 甚至比本研究总结、推理的更加复杂.

\section{4 未来研究重点}

(1) 红树林土壤 $\mathrm{pH}$ 和其他理化性质之间或直接 或间接的相互作用，形成了一个复杂且相互影响的

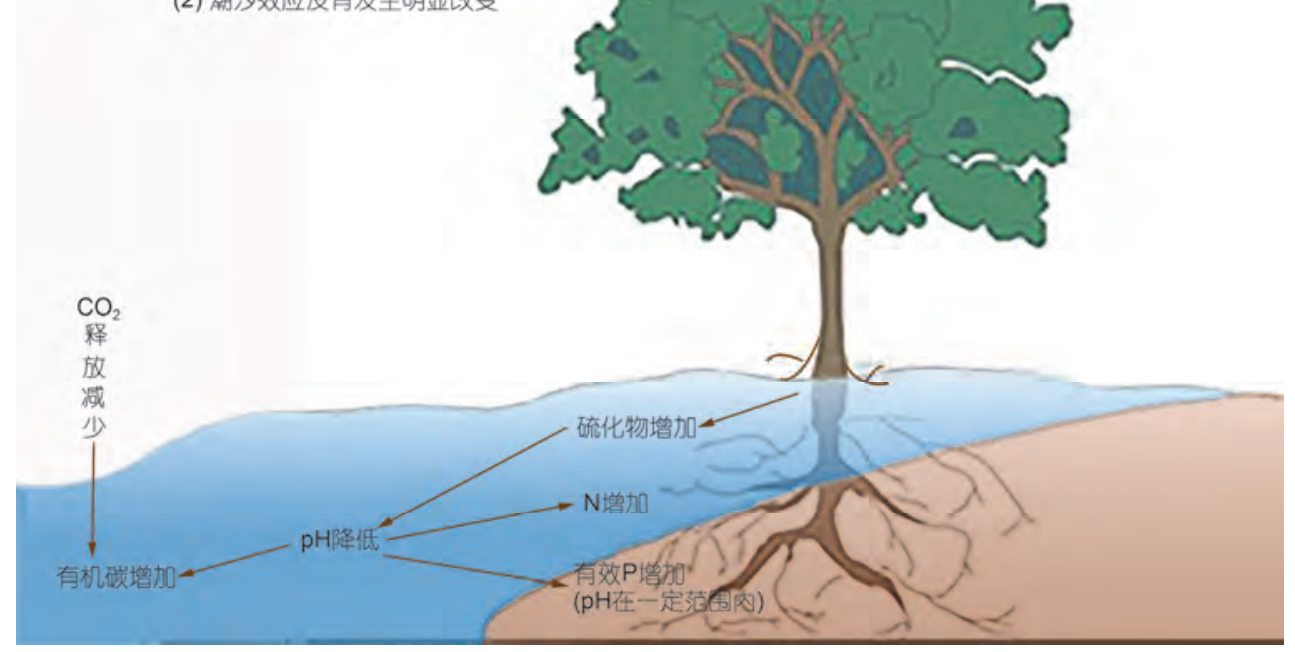

图 3 (网络版彩色)红树林修复后土壤各理化性质的变化

Figure 3 (Color online) The changes of several physicochemical properties in sediments after mangrove restoration 


\section{表 1 气候变化和人类活动对红树林土壤理化性质的影响}

Table 1 The impacts of climate change and anthropogenic activities on physicochemical properties of mangrove soil

\begin{tabular}{|c|c|c|c|}
\hline 影响因素 & 效应 & 理化性质变化 & 参考文献 \\
\hline \multirow{3}{*}{ 气候变化 } & & (1) 盐度升高 $\Rightarrow \mathrm{pH}$ 升高 $\Longrightarrow$ 有机碳含量降低 $\left(\mathrm{CO}_{2}\right.$ 释放增加 $)$ & {$[25,27]$} \\
\hline & 海平面上于 & (2) 浸没时间长 $\Rightarrow$ DO降低 $\left\{\begin{array}{l}\text { (a) } \mathrm{pH} \text { 降低 } \Rightarrow \text { 有机碳含量升高 } \Rightarrow \mathrm{CO}_{2} \text { 释放减少 } \\
\text { (b) 土壤氧化条件较差, 反硝化作用加强 } \Rightarrow \text { 土壤 } \mathrm{N} \text { 含量减少 } \Rightarrow \text { 红树 } \\
\text { 林生长受负面影响 }\end{array}\right.$ & {$[11,22,27]$} \\
\hline & 温度升高 & $\mathrm{DO}$ 降低 $\Rightarrow \mathrm{pH}$ 降低 $\Rightarrow$ 有机碳含量升高 $\left(\mathrm{CO}_{2}\right.$ 释放减少) & {$[11,22,27]$} \\
\hline \multirow{7}{*}{ 人类活动 } & \multirow{3}{*}{ 污染排放 } & (1) N 和P元素富集 $\Rightarrow$ 富营养化 $\Rightarrow$ 红树林土壤DO含量降低 $\Rightarrow p H$ 降低 & {$[49,50]$} \\
\hline & & \multirow{2}{*}{ (2) 水体环境有机物增加 $\left\{\begin{array}{l}\text { (a) } \mathrm{DO} \text { 降低 } \mathrm{p} \mathrm{pH} \text { 降低 } \\
\text { (b) } \mathrm{pH} \text { 升高(这个过程更复杂, 与有机物的种类关系密切) }\end{array}\right.$} & [27] \\
\hline & & & {$[8]$} \\
\hline & \multirow{3}{*}{ 围塘围厔 } & \multirow{3}{*}{ 土壤被池塘水浸没 \{} & \\
\hline & & & {$[11,22,25,27$,} \\
\hline & & & \\
\hline & \multicolumn{2}{|c|}{ 修复与重建 硫化物增加 $\Rightarrow \mathrm{pH}$ 降低 $\Rightarrow$ 有机碳含量升高 $\left(\mathrm{CO}_{2}\right.$ 释放减少) } & {$[9,13,22]$} \\
\hline
\end{tabular}

动态变化系统. 现阶段, 大部分研究专注于两或三个 理化性质之间的关系, 具有局限性. 通过对红树林土 壤多种理化性质进行系统的研究, 并考虑到不同季 节(干季或雨季)、潮汐状况等特定条件的影响，才能 更全面、深人掌握红树林生态系统的动态平衡.

(2) 在全球气候变化的背景下, 红树林土壤 $\mathrm{pH}$ 对红树林生态系统固碳能力影响的定量评估对衡量 红树林生态系统储碳能力和稳定性具有重要意义. 红树林土壤 $\mathrm{pH}$ 和其他理化性质的改变, 将影响土壤 中有机碳的分解和 $\mathrm{CO}_{2}$ 的释放. 通过优化土壤 $\mathrm{pH}$, 降 低土壤中有机碳的分解和 $\mathrm{CO}_{2}$ 的释放, 从而达到更好 地发挥红树林固碳能力的目的是否可行仍需要进一 步证明. 虽然, 现有研究都一再强调红树林是地球巨 大的碳库, 能够显著降低海洋生态系统对全球变暖
的反馈, 然而把 $\mathrm{CO}_{2}$ 产生通量、土壤碳含量和土壤 $\mathrm{pH}$ 串联起来, 探究红树林土壤 $\mathrm{pH}$ 以及其他理化性质之 间的动态变化对红树林土壤碳储量的影响及其机制 的研究还很少.

(3) 红树林的重建和修复需要深人探索红树林 土壤理化性质的相互关系作为依据. 在重建或修复 红树林前, 除了根据特定生境选择适合的红树植物, 还需了解其土壤的理化性质及其相互关系, 充分考 察和分析重建地土壤的理化性质，包括对修复区域 潮汐状况、污水排入情况充分的考察和分析. 例如红 树林湿地土壤条件不佳时, 是否可以通过改变某一 理化性质(如 $\mathrm{pH}$ )来推动其他理化性质的改变, 进而 起到优化红树土壤环境的目的. 未来需要更多研究 才能更准确评估修复区域土壤条件.

\section{参考文献}

1 Lin P. Mangroves (in Chinese). Beijing: The Ocean Publishing Company, 1984. 2-10 [林鹏. 红树林. 北京: 海洋出版社, 1984. 2-10]

2 Mcleod E, Chmura G L, Bouillon S, et al. A blueprint for blue carbon: Toward an improved understanding of the role of vegetated coastal habitats in sequestering $\mathrm{CO}_{2}$. Front Ecol Environ, 2011, 9: 552-560

3 Zhu Y J, Guo J L, Wu G J. Organic carbon in mangrove wetlands: A review (in Chinese). Chin J Ecol, 2012, 10: 2681-2687 [朱耀军, 郭 菊兰, 武高洁. 红树林湿地有机碳研究进展. 生态学杂志, 2012, 10: 2681-2687]

4 Zhang L, Guo Z H, Li Z Y. Carbon storage and carbon sink of mangrove wetland: Research progress (in Chinese). Chin J Appl Ecol, 2013, (4): 1153-1159 [张莉, 郭志华, 李志勇. 红树林湿地碳储量及碳汇研究进展. 应用生态学报, 2013, (4): 1153-1159]

5 Huang C L, Zheng W M. Current progresses of Chinese mangrove wetlands research (in Chinese). Wetland Sci, 2004, (4): 303-308 [黄 初龙, 郑伟民. 我国红树林湿地研究进展. 湿地科学, 2004, (4): 303-308] 
6 Duke N C, Meynecke J O, Dittmann S, et al. A world without mangroves? Science, 2007, 317: 41-42

7 Oxmann J F, Pham Q H, Schwendenmann L, et al. Mangrove reforestation in Vietnam: The effect of sediment physicochemical properties on nutrient cycling. Plant Soil, 2010, 326: 225-241

8 Jayalath N, Fitzpatrick R W, Mosley L, et al. Type of organic carbon amendment influences pH changes in acid sulfate soils in flooded and dry conditions. J Soils Sediments, 2016, 16: 518-526

9 Gong Z T, Zhang X P. Mangrove and acid sulphate soils in China (in Chinese). Acta Pedol Sin, 1994, (1): 86-94 [龚子同，张效朴. 中 国的红树林与酸性硫酸盐土. 土壤学报, 1994, (1): 86-94]

10 Wakushima S, Kuraishi S, Sakurai N, et al. Stable soil-pH of Thai mangroves in dry and rainy seasons and its relation to zonal distribution of mangroves. J Plant Res, 1994, 107: 47-52

11 Satheeshkumar P, Khan A B. Identification of mangrove water quality by multivariate statistical analysis methods in Pondicherry coast, India. Environ Monit Assessm, 2012, 184: 3761-3774

12 Ferreira T O, Otero X L, Vidal-Torrado P, et al. Effects of bioturbation by root and crab activity on iron and sulfur biogeochemistry in mangrove substrate. Geoderma, 2007, 142: 36-46

13 He Q F, Jiang Y, Liu X, et al. An analysis of soil properties of different types of mangroves in Qinzhou Bay (in Chinese). Wetland Sci Manag, 2011，(3)：45-48 [何琴飞, 蒋炎, 刘秀，等. 钦州湾不同类型红树林土壤因子调查与分析. 湿地科学与管理，2011，(3): $45-48]$

Hart M G R. Sulphur oxidation in tidal mangrove soils of Sierra Leone. Plant Soil, 1959, 11: 215-236

15 Donato D C, Kauffman J B, Murdiyarso D, et al. Mangroves among the most carbon-rich forests in the tropics. Nat Geosci, 2011, 4: 293-297

16 Neculita C M, Zagury G J, Bussiere B. Passive treatment of acid mine drainage in bioreactors using sulfate-reducing bacteria: Critical review and research needs. J Environ Qual, 2007, 36: 1-16

17 Béchard G, Yamazaki H, Gould W D, et al. Use of cellulosic substrates for the microbial treatment of acid mine drainage. J Environ Qual, 1994, 23: 111-116

18 Reinertsen S A, Elliott L, Cochran V, et al. Role of available carbon and nitrogen in determining the rate of wheat straw decomposition. Soil Biol Biochem, 1984, 16: 459-464

19 Xu S N, Chen Z Z, Li S Y. The habitat functions of mangroves for aquatic fauna and fisheries (in Chinese). Acta Ecol Sin, 2011, (1): 186-196 [徐姍楠, 陈作志, 李适宇. 红树林水生动物栖息地功能及其渔业价值. 生态学报, 2010, (1): 186-196]

20 Oades J M. The retention of organic matter in soils. Biogeochemistry, 1988, 5: 35-70

21 Guo Z H, Zhang L, Guo Y R, et al. Soil carbon sequestration and its relationship with soil pH in Qinglangang mangrove wetlands in Hainan island (in Chinese). Scient Silv Sin, 2014, 10: 8-15 [郭志华, 张莉, 郭彦茹, 等. 海南清澜港红树林湿地土壤有机碳分布及 其与 $\mathrm{pH}$ 的关系. 林业科学, 2014, 10: 8-15]

22 Zhang W J, Zeng L J, Wang W Q, et al. Soil carbon stock of Alligator weed in Min river estuarine wetland (in Chinese). Wetland Sci Manag, 2011, (1): 51-55 [张文娟, 曾陆金, 王维奇, 等. 闽江河口湿地空心莲子草土壤碳库研究. 湿地科学与管理, 2011, (1): 51-55]

23 Wakushima S, Kuraishi S, Sakurai N. Soil-salinity and pH in Japanese mangrove forests and growth of cultivated mangrove plants in different soil-conditions. J Plant Res, 1994, 107: 39-46

24 Liu R C. The studies and application on the plants' adaptability to environment of Quanzhou Bay estuarine wetland (in Chinese). Master Dissertation. Zhenjiang: Jiangsu University, 2011 [刘荣成. 泉州湾河口湿地植物环境适应性研究及其应用. 镇江: 江苏大学, 2011] Geldenhuys C, Cotiyane P, Rajkaran A. Understanding the creek dynamics and environmental characteristics that determine the distribution of mangrove and salt marsh communities at Nahoon Estuary. South Afr J Bot, 2016, 107: 137-147

26 Boto K G, Bunt J S. Dissolved-oxygen and pH relationships in northern Australian mangrove waterways. Limnol Oceanogr, 1981, 26: $1176-1178$

27 Yuwono E, Jennerjahn T, Nordhaus I, et al. Ecological status of Segara Anakan, Indonesia: A mangrove-fringed lagoon affected by human activities. Asian J Water Environ Poll, 2007, 4: 61-70

28 Dent D. Acid Sulphate Soils: A Baseline for Research and Development. Wageningen, Netherlands: International Institute for Land Reclamation and Improvement, 1986

29 Gardner W K, Parbery D G, Barber D A. The acquisition of phosphorus by Lupinus albus L. Plant Soil, 1982, 68: 19-32

30 Zhang Y C, Zhou X F, Li Q Y, et al. Effect of $\mathrm{pH}$ and $\mathrm{CaCO}_{3}$ on availability of phosphate in different forms (in Chinese). J Agric Univ Hebei, 1998, 3: 12-16 [张彦才, 周晓芬, 李巧云, 等. pH 值和碳酸钻对不同形态磷酸盐有效性的影响. 河北农业大学学报, 1998, 3: 12-16]

31 Lindsay W L, Vlek P L, Chien S H. Phosphate minerals. In: Minerals in Soil Environments. Madison: Soil Science Society of America, 1989. 1089-1130 
32 Oxmann J. Influence of substrate physicochemical properties and organic matter interactions on phosphorus dynamics in replanted mangrove forests, Southern Viet Nam. Helsinki Univ Technol, 2009, 17: iii

33 Liu X W, Zheng W J, Sun J. Global climate change and mangrove (in Chinese). Chin J Ecol, 2006, 11: 1418-1420 [刘小伟，郑文教，孙 娟. 全球气候变化与红树林. 生态学杂志, 2006, 11: 1418-1420]

34 Hensel P, Proffitt C E. Hurricane Mitch: Acute impacts on mangrove forest structure and an evaluation of recovery trajectories: Executive summary. J Organomet Chem, 2003, 690: 5383-5388

35 Short F T, Kosten S, Morgan P A, et al. Impacts of climate change on submerged and emergent wetland plants. Aquat Bot, 2016, 135: $3-17$

36 Mckee K, Rogers K, Saintilan N. Response of Salt Marsh and Mangrove Wetlands to Changes in Atmospheric CO ${ }_{2}$, Climate, and Sea Level. Netherlands: Springer, 2012. 63-96

37 Ellison J C. How South Pacific mangroves may respond to predicted climate change and sea-level rise. Adv Glob Change Res, 2000, 2: 289-300

38 Field C D. Impact of expected climate change on mangroves. Hydrobiologia, 1995, 295: 75-81

39 Banerjee K, Gatti R C, Mitra A. Climate change-induced salinity variation impacts on a stenoecious mangrove species in the Indian Sundarbans. Ambio, 2017, 46: 492-499

40 Mitra A, Banerjee K, Sengupta K, et al. Pulse of climate change in Indian Sundarbans: A myth or reality? Nat Acad Sci Lett, 2009, 32: $1-7$

41 Susan S, Qin D, Manning M, et al. Climate change2007-The physical science basis. Working group I contribution to the fourth report of the IPCC. Comput Geom, 2007, 18: 95-123

42 Komiyama A, Jin E O, Poungparn S. Allometry, biomass, and productivity of mangrove forests: A review. Aquat Bot, 2008, 89: 128-137

43 Alongi D M, Mukhopadhyay S K. Contribution of mangroves to coastal carbon cycling in low latitude seas. Agric Forest Meteor, 2014, 213: 266-272

44 Boehm F R, Sandrini-Neto L, Moens T, et al. Sewage input reduces the consumption of Rhizophora mangle propagules by crabs in a subtropical mangrove system. Mar Environ Res, 2016, 122: 23-32

45 Feng J, Zhu X, Wu H, et al. Distribution and ecological risk assessment of heavy metals in surface sediments of a typical restored mangrove-aquaculture wetland in Shenzhen, China. Marine Pollut Bull, 2017, 124: 1033

46 Onuf C P, Teal J M, Valiela I. Interactions of nutrients, plant-growth and herbivory in a mangrove ecosystem. Ecology, 1977, 58: $514-526$

47 Lovelock C E, Ball M C, Martin K C, et al. Nutrient enrichment increases mortality of mangroves. PLoS One, 2009, 4: e5600

48 Richards D R, Friess D A. Rates and drivers of mangrove deforestation in Southeast Asia, 2000-2012. Proc Natl Acad Sci USA, 2016, 113: 344-349

49 Xia P, Meng X, Li Z, et al. Sedimentary records of mangrove evolution during the past one hundred years based on stable carbon isotope and pollen evidences in Maowei, SW China. J Ocean Univ China, 2016, 15: 447-455

50 Naylor R, Burke M. Aquaculture and ocean resources: Raising tigers of the sea. Ann Rev Environ Res, 2005, 20: 185-218

51 Wu H, Peng R, Yang Y, et al. Mariculture pond influence on mangrove areas in south China: Significantly larger nitrogen and phosphorus loadings from sediment wash-out than from tidal water exchange. Aquaculture, 2014, 426: 204-212

52 Gray J S, Wu R S S, Or Y Y. Effects of hypoxia and organic enrichment on the coastal marine environment. Mar Ecol Progr Ser, 2002, 238: 249-279

53 Peng Y, Chen G, Li S, et al. Use of degraded coastal wetland in an integrated mangrove-aquaculture system: A case study from the South China Sea. Ocean Coast Manag, 2013, 85: 209-213

54 Oh R R Y, Friess D A, Brown B M. The role of surface elevation in the rehabilitation of abandoned aquaculture ponds to mangrove forests, Sulawesi, Indonesia. Ecol Eng, 2017, 100: 325-334

55 Iost S, Landgraf D, Makeschin F. Chemical soil properties of reclaimed marsh soil from Zhejiang Province, P.R. China. Geoderma, 2007, 142: $245-250$

56 Wu M, Shao X X, Hu F, et al. Effects of reclamation on soil nutrients f coastal wetland in south Hangzhou Bay (in Chinese). Soils, 2008, 40: 760-764 [吴明, 邵学新, 胡锋, 等. 围垦对杭州湾南岸滨海湿地土壤养分分布的影响. 土壤, 2008, 40: 760-764]

$57 \mathrm{Li} \mathrm{J}, \mathrm{Pu} \mathrm{L}$, Zhu M, et al. Evolution of soil properties following reclamation in coastal areas: A review. Geoderma, 2014, 226-227: 130-139

58 Jin W H, Yang J S, Wang X P. Spatial distribution of organiccarbon in coastal saline soil and its correlation with reclamation age (in Chinese). Chin Soc Agric Eng, 2013, 29: 89-94 [金雯晖，杨劲松，王相平. 滩涂土壤有机碳空间分布与围垦年限相关性分析. 农业 工程学报, 2013, 29: 89-94] 


\title{
Interactions between $\mathrm{pH}$ and other physicochemical properties of mangrove sediments: A review
}

\author{
Cong Sha ${ }^{1,2}$, Mulan Wang ${ }^{1,2}$, Yuelu Jiang ${ }^{1 *} \&$ Guanghui Lin $^{1,3}$ \\ ${ }^{1}$ Graduate School at Shenzhen, Tsinghua University, Shenzhen 518000, China; \\ ${ }^{2}$ School of Environment, Tsinghua University, Beijing 100084, China; \\ ${ }^{3}$ Department of Earth System Science, Ministry of Education Key Laboratory for Earth System Modeling, Tsinghua University, Beijing 100084, China \\ * Corresponding author, E-mail: jiang.yuelu@ sz.tsinghua.edu.cn
}

Mangrove ecosystem provides a broad array of ecological services including carbon fixation and storage, pollution prevention, water purification and maintaining a high level of biodiversity. However, mangrove systems cannot migrate, these wetlands are now facing a slew of serious threats from climate change and human activities that shrinking mangrove habitats intact, ecosystem structure and its ecological functions. A net loss can be expected in many of these ecosystems. Key physiochemical properties of mangrove sediments such as $\mathrm{pH}$, nutrient contents, and salinity, play important roles in regulating mangrove growth and their ecosystem functions. Different physiochemical properties of mangrove soils can influence each other through microorganism activities or chemical reactions. When changes in one physiochemical factor are accompanied by changes in another, it will adversely affect mangroves and even the entire ecosystem. In order to maintain the carbon fixation and storage functions of mangrove ecosystem, it is an emerging priority to keep the $\mathrm{pH}$ of mangrove soil fluctuate in a reasonable range. Mangrove sediments are usually acid-sulphate soils with high sulfur content, and their $\mathrm{pH}$ are generally negatively correlated with total sulfur content. Total mass, species, density, distribution, and population structure of mangroves directly affect the soil sulfur content. The oxidation state of the soil, sulfur content, and the speciation and distribution of sulfides are important factors in determining the soil $\mathrm{pH}$. Meanwhile, the $\mathrm{pH}$ is also affecting the sulfide minerals in mangrove soil. Moreover, the intake and decomposition of organic matter in mangrove soil is an ongoing process, in which the organic carbon content and its speciation affect soil $\mathrm{pH}$ by changing the population structure, growth, and physiological processes of soil bacteria. Concurrently, the balance of soil $\mathrm{pH}$ affects the organic carbon content and its speciation in the mangrove soil. There is generally a positive correlation between $\mathrm{pH}$ and salinity in hyperhaline mangrove soil; however, whether salinity directly affects or indirectly affects $\mathrm{pH}$ changes remains to be further studied. Thus, systematic studies on the destruction, protection and reconstruction of mangroves are urgently needed. In this review, we summarized our current understandings focusing on the $\mathrm{pH}$ of mangrove sediments and its interactions with other physical and chemical properties including salinity, sulfur, organic carbon, dissolved oxygen, nitrogen, and phosphorous contents. We also examined the possible impacts on the $\mathrm{pH}$ and other physiochemical properties of mangrove sediment from climate change and human activities, such as sea level rise, pollution discharge and mangrove restoration. Moreover, the effects of these changes on structure, functions and ecological services of mangroves ecosystems were evaluated. The research contents and analysis methods reviewed in this article have important reference significance for the carbon storage capacity, restoration and reconstruction of mangroves.

mangrove, climate change, human activity, $\mathrm{pH}$, nutrient content

doi: 10.1360/N972018-00369 